\title{
Costume Development Model for Tourism Promotion in Mae Hong Son Province, Thailand
}

\author{
A. Sarobol ${ }^{1}$ \\ ${ }^{1}$ Faculty of Humanities, Chiang Mai University, 50200 Chiang Mai, Thailand
}

\begin{abstract}
This research aims to study Pha Bong community's dressing style and to develop a new ethnic costume that shows their identity to promote tourism in the province. Pha Bong Community is a community in Maehongson Province where two ethnic groups, people of Tai Yai (Shan) and Sakor Karen, co-exist. The data collection methods include focus group and in-depth interview with target population, small group discussion and review of literature on costume development. The obtained data were then submitted to content analysis. First, it was found that they both have their own identity, resources, network marketing and inherited wisdom from their ancestors. Each group runs their business separately. Secondly, the research resulted in the creation of a new costume for the Pha Bong community created by members of two ethnic groups. This costume combines Karen symbol with Tai Yai (Shan) clothing style. The motif and pattern of the fabric identify community members' lifestyle, belief and value. It is recommended that development should be planned upon available resource and the need of the community. In addition, the community leader should encourage members to take parts in management and to cooperate for a sustainable development.
\end{abstract}

\section{Introduction}

Mae Hong Son is a province located in the northern part of Thailand. Being surrounded by mountains and forests and a home for multi cultures, the province is suitable for cultural tourism. Ban $\mathrm{Pa} \mathrm{Pu}$, located in Tambon Pha Bong, Muang district, Mae Hong Son Province, is a culturally blended community where Tai Yai(Shan) and Karen Sakor coexist. These two ethnic groups, living harmoniously and generously, have their own ethnic identity. Members of Karen Sakor join together when weaving. Tai Yai(Shan) team up for cooking and running homestay.

Each ethnic group has their unique traditional costume. In addition, Tambon Pha Bong has its own ethnic food and natural hot springs. This makes the community an ideal place for tourism. Institute of Tourism Authority of Thailand, Chiang Mai Provincial Health Office and the Faculty of Humanities, Chiang Mai University, have selected Pha Bong community to be a prototype community for Healthy-Based Tourism. Thus, the community members or the two ethnic groups were asked to look for a costume that represents their ethnic identity and that can be a symbol of Pha Bong community. This costume development would support tourism activities in Mae Hon Sorn province. 
This research was conducted by using participatory process study (Atchara sarobol, 2006). Two ethnic groups exchanged their knowledge, cooperated and received shared benefits. They brainstormed together, collected information on resources, culture and community costumes via SWOT analysis which included in-depth interviews, focus group and participatory workshops led by people who had knowledge and experience from two ethnic groups. The objectives of the study were to study the identity of costumes in Pha Bong community and to develop a costume for Pha Bong community to promote tourism.

\section{Methodology}

This qualitative research study collected data from targeted samples. The samples consisted of four experts in local costume and 10 community members, drawn from two ethnic groups, who attended participatory workshops. The procedures were as follows:

1. Meetings with the villagers to do SWOT Analysis on the topics related to ethnicity, cultures, intellectual resources in their community.

2. Focus groups and participatory observation with the people who had knowledge and members of the two ethnic groups to get the villagers' costumes information and find the identity of villagers' costumes and develop their costumes symbol together.

3. Collecting historical information on villagers' costumes by in-depth interviews to get the meanings, the values, beliefs of patterned fabric in the community.

4. Participatory workshops on the topics related to the style of costume, yarn dyed woven from natural materials and creating symbolic garments with embroidery.

5. Review of the related literature.

\section{Data Analysis and Discussion}

It was found that the strengths of the Pha Bong Community were group management i.e., Karen Sakor's weaving group and Tai Yai (Shan)'s homestay group, their own identity (the Shan and Karen ethnic group, having raw materials, network, succession as well as network marketing. The weakness was that the lack of a database for tourism management operated by the community. The overall tourism management was split into parts. An opportunity for community to develop was collaboration between the two ethnic groups in designing costume. The challenge was identified as separate management by each ethnic group.

\subsection{The Process to Find Identities and Clothing Styles of Pha Bong Community}

The findings from the group discussion between members of the two ethnic groups and the researchers showed that the new dress pattern should blend the identity of each ethnic group together while keeping the unique symbol of each group. A Tai Yai(Shan) expert mentioned that Tai Yai(Shan) shirt looked like Lanna shirt. It had front crossing three-part sleeves with no arms. The arm or sleeve was attached to the shirt without stitching. The collar runs along the neckline and one edge goes down to touch the front flap. The sarong is a skirt with front fascia. As for Karens, their outstanding symbol is the unique pattern whose meanings were influenced by beliefs of their ancestors. 
Karen experts said that the White Karen (Sakor group) had an ancient belief that the pattern on Karen's clothes came from the pattern of a big snake skin. Four popular patterns for weaving and embroidery were Yo-ho-gue, Gue-pe-pe-lo, Chui-ko-law, and Tee-kha. Only one pattern "Gue-pe-pelo" was selected because it was associated with good fortune. This pattern displays round flowers. The perfect pattern has eight flowers with the connecting lines between them and embroidered at the cuffs in combination with other elements. The fabric used was the hand-woven cloth with the loom and dyed yarn from natural tree bark found in the wild in season.

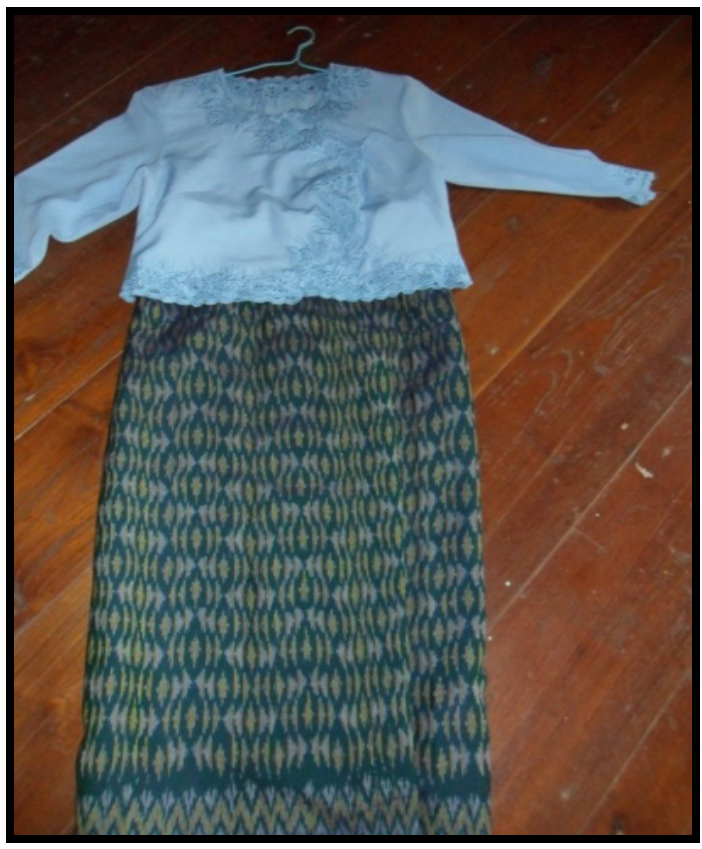

Figure 1. The Tai Yai(Shan) women dress

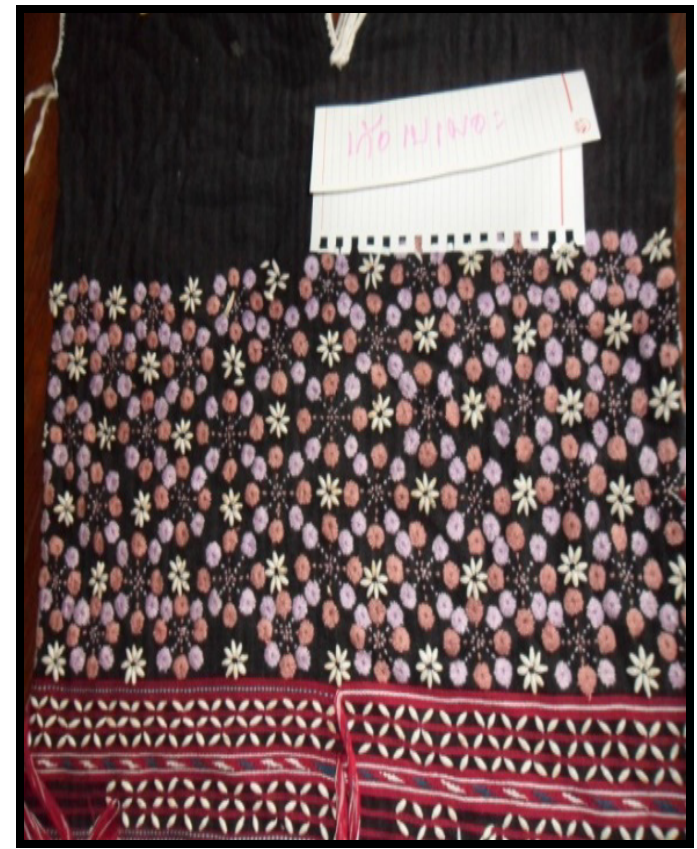

Figure 2. The "Gue-pe-pe-lo" pattern

\subsection{Dressing Style of Pha Bong Community}

Pha Bong community costume style reflects Tai Yai (Shan) characteristics. The shirt was front crossed, 3-part sleeves. The original Tai Yai(Shan) shirt did not have arms and used the strap handweaving cloth of the Karen with embroidery around the neck and flap with the original Karen's pattern "Gue-pe-pe-lo". Long sarong was seam sewing with waistband, front flap like that of the Tai Yai(Shan). At the bottom of sarong was made of the same design of "Nam Lai" like Karen's sarong. The sarong was made from the strap hand-woven cloth, dyed with natural raw materials available in the community.

After the group discussion, the women's group members agreed to join the workshop on natural dyes and workshop on symbolic garments' embroidering. The knowledge was transferred from the experts in each ethnic group. The Karen experts trained Tai Yai participants on how to dye yarn. The woven fabric by the Karen were sewn by Tai Yai group members into garments such as cotton shirt and sarong. The women from both ethnic groups exchanged their knowledge on garments' embroidery. 
3.3 Workshop on Natural Dyeing fabric embroidery.
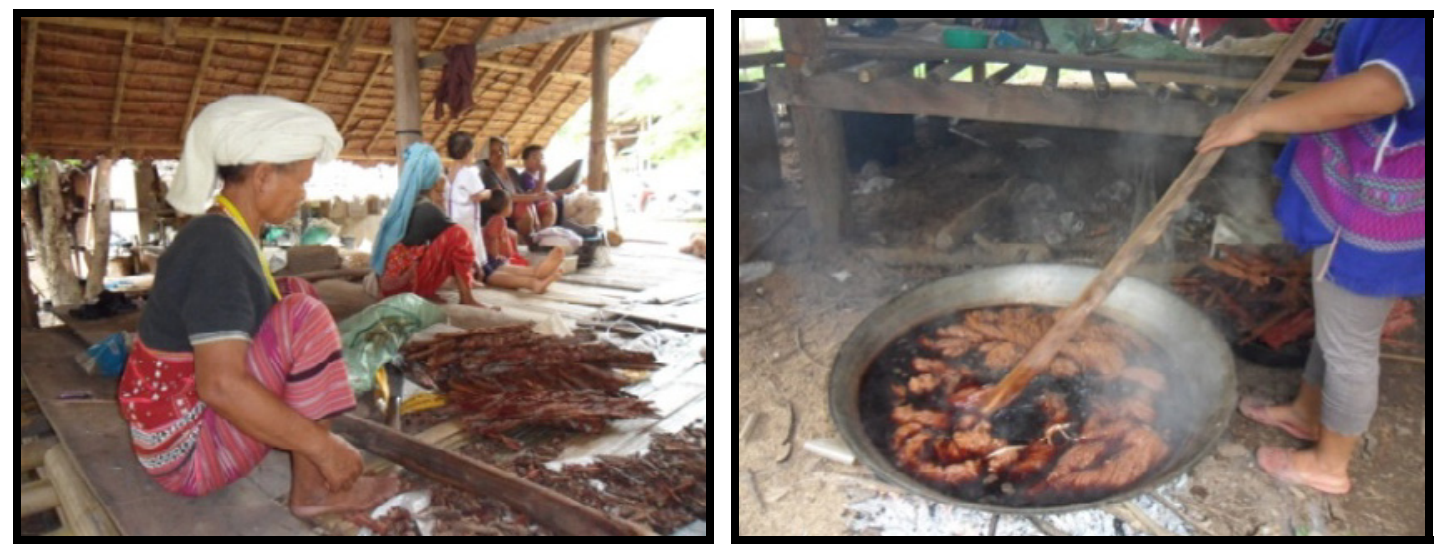

Figure 3. Demonstration of natural dyeing steps
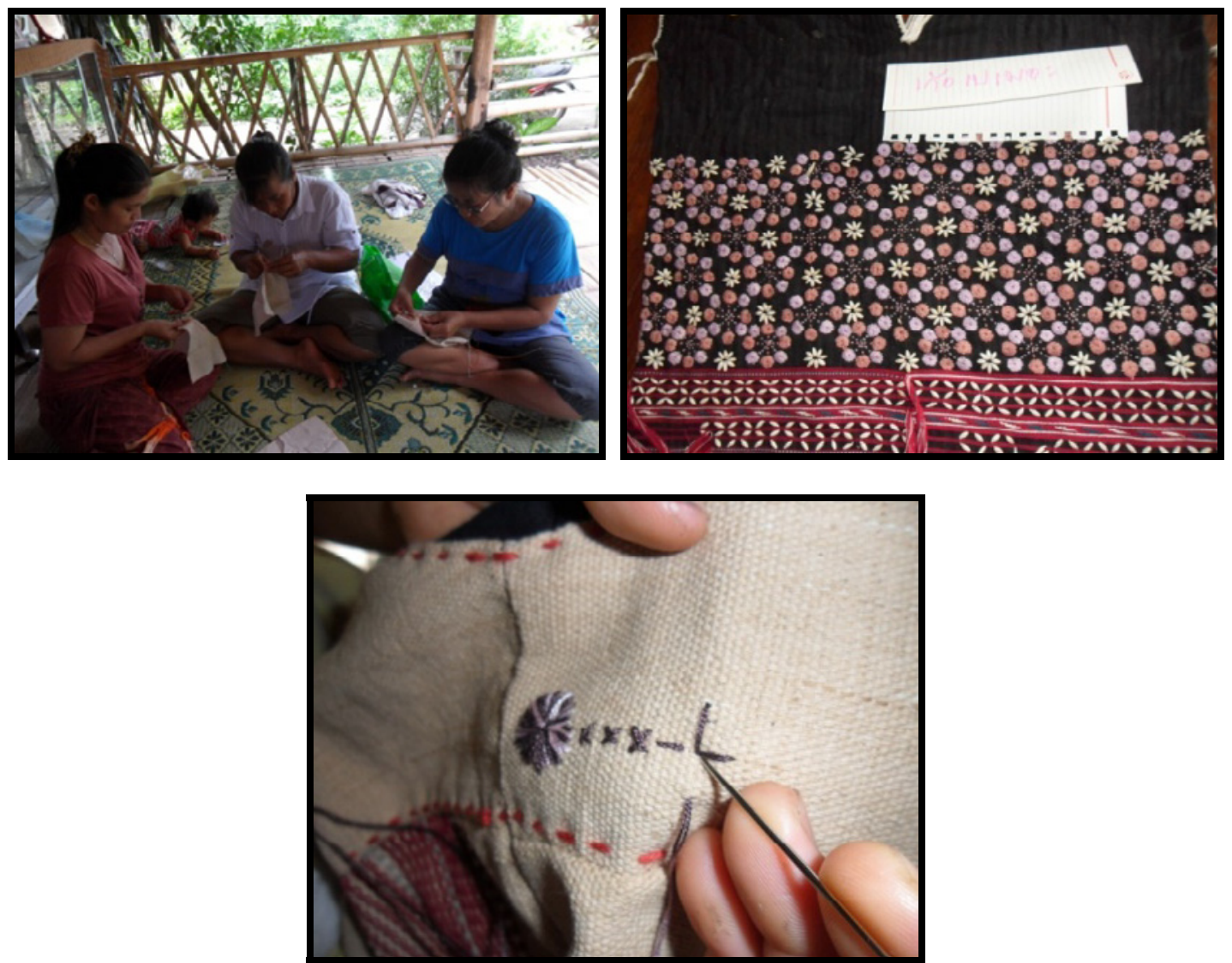

Figure 4. Workshop on fabric embroidery 

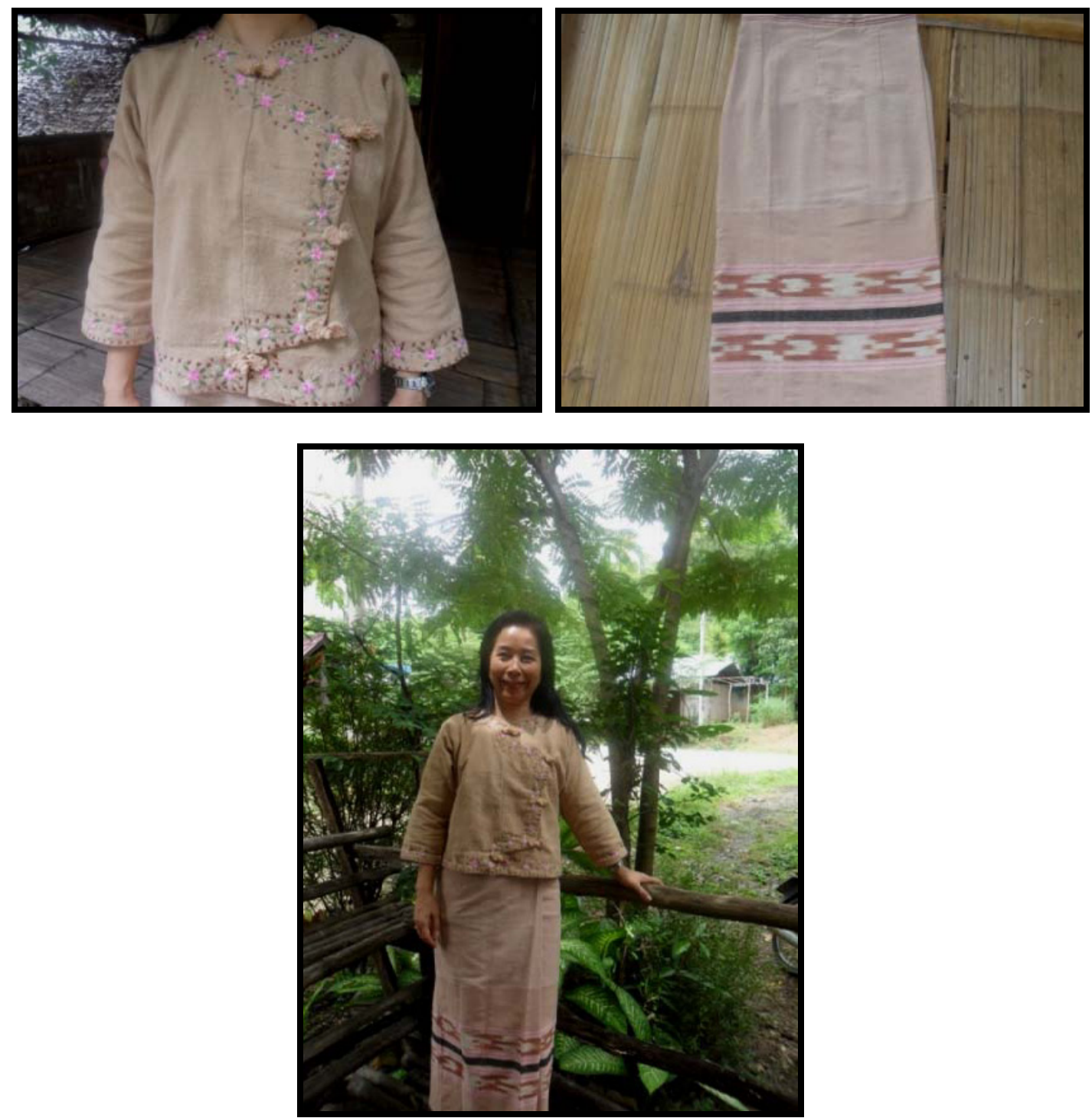

Figure 5. The clothing style of the Pha Bong Community, combining Shan and Karen identity

\section{Discussion}

At Pha Bong Community, Mae Hong Son province, the community members had developed the costume design with mixed symbols of the two ethnic groups. This was to combine clothing style of the Tai Yai(Shan)'s and the "Gue-pe-pe-lo" pattern of Karen embroidery along the shirt and "Lai Nam Lai" pattern at the bottom of the sarong to show the identity of the community. Both traditional dress of ethnic Tai Yai(Shan) and original pattern of ethnic Karen truly reflect the wisdom of dressing that has been handed down from their ancestors, from generation to generation. The costume reflects a hidden belief that has a lot of value to the mind of the community's members who took part in developing the prototype costume, by using available materials in the community and exchanging local wisdom. This is counted as creating a new identity for the community to promote tourism. This collaboration is consistent with the concept that the members must participate in thinking, analyzing, and operating as well as enjoying the benefits together. It also supports the identity concept of the 
members in using the symbol of each ethnic group to determine the identity of the garment. Even though it is a reproduction under a different context (with some modification), the symbol remains the same. The product reflects self-reliance as it is produced by using raw materials available in the community and through exchanging local wisdom. This is in accordance with the concept of community tourism by Sin Sarobol (2003), "the CBT is tourism by residents who own resources, make us of the available resources as a cost factor or travel arrangements appropriately accordingly. The resource may include nature, cultural traditions, lifestyle, production methods as well as selling products with its own identity such as handicrafts and textile.

\section{Recommendation}

The development of the clothing patterns should be in the community with the available raw materials, skills related to textile production, community-based tourism management, network, and with the need to wear a costume for everyday life purpose or for special occasions. This can be further developed as a souvenir reflecting a unique sense of community which promotes local tourism.

\section{References}

1. B. Ornkhan and S. Srichamnong, Participatory Procedure, Chiang Mai: B.S. Printing [Thai] (2001)

2. Y. Santasombat, Lak Chang: A Recreation of Tai Identity in Taikong, Bangkok: Amarin Printing and Publishing Limited, [Thai] (2000)

3. S. Salobol, Tourism by Community, Chiang Mai: Wanida Press, [Thai] (2003)

4. Office of the National Research Board,Guidelines for the People to Participate in Rural Development. Bangkok. Kurusapha Printing, [Thai] (1995)

5. A. Fuengfoosakul, Identity, Bangkok: Tiger Printing, [Thai] (2003)

6. A. Sarobol, Participation of Doi Tao Community in Developing the Wisdom on Textile, Doctoral dissertation, Academic Disciplines on Rural Planning and Development Graduate School, Mae Jo University, [Thai] (2006)

7. T. O'riordan, Globalism, Localism and Identity, London: Earthscan Publications Ltd,(2001)

8. United Nation Development Programe, UNDP guidebook on Participation, The concept of Participation in Development, (online) http://www.undp.org/essopp/paguide1.html.

9. http://www.taiyai.org/index.php?name=suites\& file=readsuites\&id=1 